\title{
Co-developing climate services for resilient public health system in India
}

\author{
Abha Tewary ${ }^{1, *}$, Rajeev Kumar Mehajan ${ }^{2}$, Mahaveer Golechha ${ }^{3}$ and \\ Dileep Mavalankar ${ }^{3}$
}

${ }^{1}$ Independent Researcher, Mhow 453 441, India

${ }^{2}$ Science and Engineering Research Board, DST, GoI, New Delhi 110 070, India

${ }^{3}$ Indian Institute of Public Health, Gandhinagar 382 042, India

The efficient and effective management of climate risks is dependent on the availability of reliable climate information and services. To make health system resilient towards the impacts of climate variability and change, climate-related data and information need to be routinely integrated into health science, practice and policy making. The present paper studies the policy congruence at international, regional, national and sub-national levels for climate services for public health, with specific focus on India; to identify the gaps in understanding and possibly suggest a roadmap for co-developing climate services for the public health sector in India.

Keywords: Adaptation, climate resilience, climate services, public health.

Climate change affects almost every facet of human life and the impacts transcend the state borders. The observed changes in the climate system suggest that 'warming of the climate system is unequivocal. Especially since the 1950 s, many of the observed changes are unprecedented over decades to millennia.' The climate projections further indicate that 'continued emissions of greenhouse gases will cause further warming and changes in all components of the climate system, ${ }^{1}$.

There is very high confidence within the scientific community that 'health of human populations is sensitive to shifts in weather patterns and other aspects of climate change ${ }^{2}$. The impact of climate change has directly and indirectly threatened human health through rising sea levels, increasing temperatures, negative impact on water and food supply, extreme weather events like droughts, floods, earthquakes, etc. as well as susceptible shelter and population migration.

The direct impacts are due to rapid onset events like changes in temperature resulting in heat waves or cold waves; changes in precipitation resulting in floods, storms or droughts, disasters and severe weather conditions which cause social, economic and environmental disruptions and adversely impact both physical and mental health ${ }^{3,4}$.

\footnotetext{
*For correspondence. (e-mail: abhatewary@gmail.com)
}

Indirect impacts include climate-induced illnesses, for example, increased incidences of heat waves related deaths, vector-borne and water-borne diseases, and effects of failure of crops due to extreme onset events. Indirect impacts also include damage to health infrastructure, energy and power supplies in case of rapid onset events, which lead to disruption of essential health services. Lifecycles of water, food and vector-borne pathogens are significantly affected by climatic factors through ecological and biological processes ${ }^{5}$.

The relatively slower onset events like sea level rise, ocean acidification, glacial retreat, loss of biodiversity, etc. adversely affect availability of drinking water, soil quality and land degradation. These cause indirect impacts on social effects like climate induced displacement and migration ${ }^{3}$. These impacts are 'expected to put additional stress on human well-being and equity through intragenerational and inter-generational health outcomes ${ }^{6}$.

COVID-19 pandemic has globally exposed the limited preparedness and capacity of health systems in combating mass health risks of vulnerable population. Climate change may indirectly affect COVID-19 response, as it undermines environmental determinants of health and places additional burden on health systems and service delivery.

In India, climate services are being effectively utilized for sectors such as agriculture, shipping, fishing and water resource planning, however the effective demand for climate services from the health community is low or non-existent. The efficient and effective management of climate risks is dependent on the availability of reliable climate information and services. To make health system resilient towards the impacts of climate variability and change, climate-related data and information need to be routinely integrated into health science, practice and policy making.

\section{Climate risks to public health in India}

Global climate change and associated climate variability will have severe implications for human health, with disproportionate effects on India. The country is already facing public health and healthcare delivery challenges, 
including scarcity of healthcare resources, higher burden of endemic infectious disease, and substantial inequalities in access to healthcare.

To create effective public health responses to climate change impacts, it is important to develop a baseline understanding of the region-specific demographic, social and ecological determinants of health.

India is the seventh largest country in the world. Due to diverse physiographic regions in the country, climatic conditions vary significantly; from alpine in the northern Himalayan belt to tropical in the south and desert in the west. There are four major climatic groupings; tropical wet, tropical dry/desert, subtropical humid and mountain climate $^{7}$.

There are four seasons in the subcontinent; relatively dry and cold winters (December to February); dry hot summer (March to May), southwest monsoon (June to September) and retreating or northeast monsoon (October to November). In winter, the northern mountains and plains experience extreme cold, often marked by cold waves. In hot summer, maximum temperatures are in excess of $48^{\circ} \mathrm{C}$. Summer is marked by violent thunderstorm activity over land and tropical cyclone originating over the seas and thereafter moving inland. Southwest monsoon is marked by heavy rainfall spells, often causing floods and inundation. The retreating monsoon brings rainfall to Tamil Nadu and adjoining areas and frequent cyclone activity over the Bay of Bengal ${ }^{7,8}$.

India is also a developing economy with second highest population in the world. According to the Census of India 2011, India's population stands at 1.21 billion, with a decadal growth rate of $17.7 \%$. Almost one-fifth of the world population $(17.5 \%)$ inhabits India, which has $2.4 \%$ of the world's surface area ${ }^{9}$. High population density is a cause of concern for planners and policymakers in the arena of weather and climate.

The vulnerability of population to climate change impacts varies depending on 'a range of social, economic, historical and political factors, all of which operate at multiple scales, ${ }^{10}$. As per the latest estimation of poverty by the 'Expert group' of the erstwhile 'Planning Commission', in 2011-12, 29.5\% of the Indian population was below poverty line (BPL); with $30.9 \%$ of rural and $26.4 \%$ of urban population ${ }^{11}$.

The IPCC 'Special Report on Global Warming of $1.5^{\circ} \mathrm{C}$ ' states with high confidence that high percentages of the poor in Africa and Asia would be most vulnerable due to exposure to climate-related risks for temperature increase between $1.5^{\circ} \mathrm{C}$ and $2^{\circ} \mathrm{C}$. The projections also indicate increase in frequency and duration of warm spell lengths, substantial increase in heavy precipitation events, increased flood risk, increased coastal flooding risk and decreasing tropical crop yield in South Asia ${ }^{12}$. With its huge and increasing population and rapid urbanization, climate change as a stressor would only magnify the existing health threats.
Many infectious diseases, including water-borne, are highly sensitive to climatic conditions. Climate change lengthens the transmission season and expands the geographical range of many vector-borne diseases. Increased temperature and consequent heat waves can make working conditions unbearable and increase the risk of cardiovascular, respiratory and renal diseases.

\section{Climate services: mainstreaming adaptation and climate risk management}

Climate variability, particularly on sub-seasonal to interannual time scales, is important for decision making in dealing with climate-sensitive health impacts, at policy, community as well as individual levels. Climate stressors like temperature, flooding, drought, sea level rise or storm surge impose different climate risks to vectorborne diseases, water-borne diseases, nutrition, health systems and infrastructure and other risks to marginalized populations, as well as direct physiological and psychological risks. Climate services can make a difference through providing actionable early warnings based on historical climate information as well as future predictions. In addition to adaptation, climate services support climate-related risk management.

Climate services for health is an emerging field with an objective to support public health practitioners and policymakers for understanding the impact of climate change and extreme weather events on human health. It bridges the 'usability gap' between useful knowledge outputs and usable climate information by connecting the 'users' and 'usable information' through stakeholder collaboration $^{13-15}$. The provisioning of 'usable information tailored to end user needs ${ }^{15}$ improves decision making with 'actionable information product' 1 .

The Global Framework for Climate Services (GFCS) envisions 'to enable better management of the risks of climate variability and change and adaptation to climate change, through the development and incorporation of science-based climate information and prediction into planning, policy and practice on the global, regional and national scale ${ }^{17}$. GFCS focuses on five priority areas including health.

\section{Why this paper?}

To build climate resilience in health systems, synergies are required between climate and health sectors for implementation of adaptation measures. This paper attempts to study the policy congruence at international, regional, national and sub-national levels for climate services for public health, with specific focus on India. It also highlights the co-benefits of climate services for health. It is a joint take from the perspective of climate scientists and public health professionals on the existing structures of 
governance, to identify the gaps in understanding and possibly suggest a roadmap for co-developing climate services for the public health sector in India.

\section{Public health status in India}

As per India's National Health Profile 2019, the average life expectancy at birth was 68.7 years in 2012-16; 67.4 years for rural areas and 72.2 years for urban areas ${ }^{18}$. The National Health Policy (NHP) of India 2017 endorses the use of disability-adjusted life years (DALYs) to estimate burden of disease in India. DALY is a health metric that quantifies the burden of disease from morbidity and mortality. One DALY equates one lost year of healthy life ${ }^{19}$.

Currently, non-communicable diseases dominate over communicable diseases in the total disease burden of the country. A 2017 report of India Council of Medical Research (ICMR) estimated that communicable, maternal, neo-natal and nutritional diseases contributed to $33 \%$, non-communicable diseases to $55 \%$ and injuries to $12 \%$ of the total disease burden measured as DALYs. Within the Indian sub-continent, vector-borne communicable diseases like malaria, dengue, chikungunya, Japanese encephalitis, kala-azar and filaria; and water-borne diseases like cholera, diarrhoea, typhoid and viral hepatitis result in high morbidity and mortality. Over the last 26 years, the share of communicable diseases has dropped in the overall burden of disease, whereas the share of noncommunicable diseases has increased ${ }^{20,21}$. However, this 'epidemiological transition' varies across different states of the country. India has made a significant advancement in public health indicators, e.g. significant decline in India's infant mortality rate and maternal mortality ratio. The medical education infrastructure in India has also grown rapidly, with more than 530 medical colleges and 310 dental colleges ${ }^{18}$.

Recently, the Government of India (GoI) has implemented Ayushman Bharat Mission-Pradhan Mantri Jan Arogya Yojana (PMJAY), world's largest health scheme, for expanding health insurance net to a target population of 10 crore, covering the poor and the deprived. The scheme aims to provide a cover of INR 5 lakh per family per year for secondary and tertiary care procedures ${ }^{22}$.

In order to understand the Health-Climate dynamics better, let us first explore the governance and policy structures at global, regional and national levels.

\section{Climate change and health: global governance}

The policy architecture for governance of climate change at global level has evolved over a period of time ${ }^{23}$. Several international agreements and instruments have recognized the urgency for climate action.

The GFCS was formulated in 2009 for developing climate services for five priority areas, including health.
The Climate Services Partnership was established in the first 'International Conference on Climate Services' (ICCS1) in 2011.

In 2014, the World Health Organization (WHO) developed 'Guidance to protect health from climate change through health adaptation planning' to include health in the "National Adaptation Plan"24. WHO and WMO collaborated for the 'Climate Services for Health Case Study Project' and brought out 40 case studies in 2016.

WHO conducted the first 'WHO Health and Climate Change Survey' in 2015. The data from the second survey in $2017 / 18$ was used to develop health and climate change country profiles, indicating climate risks and associated likely impacts on health ${ }^{25}$. India did not participate in both the surveys.

Goal 3 of the '2030 Agenda for Sustainable Development' adopted in 2015, pertains to 'Good health and wellbeing' and Goal 13 to 'Climate action, 26 .

The Paris Agreement adopted in 2015, set forth the 'Nationally Determined Contributions (NDCs)', a legally binding obligation for all country parties. The 'Preamble' to the Agreement acknowledges that the country parties should 'respect, promote and consider their respective obligations on $(\ldots)$ the right to health $(\ldots)^{, 27}$.

\section{Climate change and health: regional linkages}

At the regional level, there are a diverse set of collaborations involving state as well as non-state agencies for action on climate change and health. This segment focuses on such linkages, particularly for South East Asia.

\section{C3S and I-DARE}

Copernicus, the 'Earth Observation Programme'28 of the European Union, provides services in six thematic areas including Climate Change. The 'Copernicus Climate Change Services' (C3S) offer climate data and tools in the public domain and serve as an important resource to GFCS $^{29}$. WHO and C3S collaborated to develop 'International Data Rescue' (I-DARE), the data rescue portal of GFCS, for data rescue activities across the nations ${ }^{30}$. India has been part of I-DARE projects for (a) Climatological Data Digitization, (b) Digital Photography of Analysed Weather Charts and (c) Digitization of Autographic Charts ${ }^{31}$.

\section{RCOFs}

The GFCS is implemented at regional level through WMO's pre-existing Regional Climate Outlook Forums (RCOFs), operational since the late 1990s. Currently, WMO has 19 RCOFs under six regional associations, 
mainly covering least developed and developing countries $^{32}$.

India is part of South Asian Climate Outlook Forum (SASCOF) established in 2010. It is coordinated by India Meteorological Department (IMD) - the National Meteorological Service (NMSs) of India, and Indian Institute of Tropical Meteorology (IITM), Pune.

Sessions of the Climate Services User Forums (CSF) are held in conjunction with SASCOF sessions to promote stakeholder interaction at regional level. There are programmes funded by grants for 'implementing GFCS at regional and national scales'. Two such projects were implemented in India during 2013-2017.

\section{Regional integrated multi-hazard early-warning system for Asia and Africa (RIMES)}

RIMES is 'an international and intergovernmental institution (...) for the generation and application of early warning information, ${ }^{33}$. Including India, RIMES has 12 member nations from Asia and Africa, along with 19 collaborating countries. It covers six thematic areas namely (1) weather and extreme events, (2) water-related hazards, (3) seasonal climate, (4) earthquake and tsunami, (5) climate change and (6) societal application. It provides key services to member states, their NMSs and national and local level institutions across thematic areas.

\section{Male declaration}

The member states of WHO South-East Asia Region adopted the 'Male Declaration' in 2017 for 'building health systems resilience to climate change, 34 . The core action points of the declaration include 'raising public and policy awareness on the health impacts of climate change; integrating climate risks into health policy, enhancing health sector preparedness to climate risks; establishing and strengthening climate change and health information systems and research', ${ }^{34}$. The 'Framework for Action' of the declaration is to be implemented during 2017-2022.

\section{Climate change and health: Indian Policy Landscape}

India has implemented a series of sector-specific and centrally sponsored policies aimed at achieving sustainable development. There are several national key policies related to urban sanitation, urban transport, urban housing and habitat, agriculture, water, environment, disaster management, etc. which indirectly support climate change adaptation by promoting resource efficiency and reducing exposure to health risks.

The 'Prime Minister's Council on Climate Change' (PMCCC) constituted by GoI in 2007 was the first concerted effort to explicitly address climate change concerns within the country.

\section{The National Action Plan on Climate Change}

The National Action Plan on Climate Change (NAPCC) launched by PMCCC in 2008 'outlines a number of steps to simultaneously advance India's development and climaterelated objectives of adaptation and mitigation, ${ }^{35}$. NAPCC has eight 'National Missions', out of which five are focused on adaptation namely national missions on Water, Sustainable Agriculture, Himalayan Ecosystem, Green India and Strategic Knowledge for Climate Change ${ }^{36}$.

After adoption of the Paris Agreement, the addition of four new missions to India's NAPCC was proposed, including one on 'Health'. The proposed 'National Action Plan for Climate Change and Human Health' has been submitted for approval ${ }^{37,38}$.

The states have their respective 'State Action Plan on Climate Change' (SAPCC) aligned with the NAPCC strategy embodying decentralization of climate change actions and focused on state-specific vulnerable sectors.

Only a few states have included adaptation activities for the health sector in their SAPCC, with minuscule budget. Gujarat and Uttarakhand have allocated $1 \%$ of their total estimated budget, Odisha 3\%, Madhya Pradesh $9 \%$ and Mizoram $8 \%$ (ref. 39).

\section{National Adaptation Fund on Climate Change}

National Adaptation Fund on Climate Change (NAFCC) was launched in 2015 for 'scaling-up climate change adaptation interventions in accordance with the NAPCC and $\mathrm{SAPCC}{ }^{40}$. Its objectives include (a) funding adaptation projects/programmes associated with relevant missions under NAPCC and SAPCC; (b) preparing climate scenarios, vulnerability assessments and climate impact assessment; (c) capacity building on adaptation, and (d) knowledge management ${ }^{40}$.

A total of 30 projects was sanctioned under NAFCC in 2018-19 and none pertains to climate change adaptation in the health sector ${ }^{41,42}$.

\section{Climate Change Action Programme}

Climate Change Action Programme (CCAP) was approved by GoI in 2014 with an objective to 'create and strengthen the scientific and analytical capacity for assessment of climate change in the country ${ }^{41}$. CCAP is focused on research and capacity building.

\section{India's NDCs}

India's NDCs have eight goals towards pre-2020 climate actions. The adaptation goals pertain to sustainable 
lifestyles, climate-friendly growth, enhanced investment in development programmes in sectors including health, climate finance, capacity-building and technology trans$\operatorname{fer}^{36,43}$.

\section{Public expenditure on adaptation}

The 'development spending' on vulnerable sectors is an indicator of its building adaptive capacity. In 2014-15, India's public expenditure on 'adaptation' was INR 2130 billion, i.e. $12 \%$ of the total union budget for the year, approximately $2 \%$ of the GDP; $10 \%$ of this budget was allocated for 'health and family welfare' ${ }^{44}$.

\section{NHP 2017}

NHP 2017 aims to provide 'universal access to good quality healthcare services ${ }^{45}$ at affordable cost. It is focused on 'curative care' and recognizes linkages between 'social determinants of health' and 'health outcomes'; however, it is completely silent on 'environmental determinants of health'. The terms 'climate change' and 'adaptation' do not find a single mention in the policy document.

\section{National Health Mission}

National Health Mission (NHM) is an overarching mission with two sub-missions focused on disease control, prevention and surveillance. National Rural Health Mission (NRHM) launched in 2005 aims to 'meet people's health needs in rural areas, especially the vulnerable, ${ }^{46}$. National Urban Health Mission (NUHM) launched in 2013 aims to 'effectively address the health concerns of the urban poor population, 47 .

The unique feature of NRHM is the convergence of all health-related schemes under one umbrella mission. It focuses on decentralization, with 'District Health Plans' as the main instrument for public health planning and 'Community Participation' as an important link between health system and the community. NUHM seeks to promote inter and intra sector coordination. Climate change adaptation aspects however are not visible anywhere in the 'Framework on Convergence' of $\mathrm{NUHM}^{48}$.

The 'National Programme on Climate Change and Human Health' approved under NHM in 2019 has Ministry of Health and Family Welfare (MoHFW) as the nodal ministry and National Centre for Disease Control (NCDC) as the nodal technical agency. Premier institutes have been identified as Centre of Excellences for technical support ${ }^{38}$.

India follows a quasi-federal system of governance, with division of power at federal and state levels. India's constitution has public health in 'State list', hence health is a state subject. The federal government is responsible for developing various policies. The state governments are responsible for policy implementation and for providing health services to the citizens.

\section{Building climate resilience in health: sub-national initiatives}

A few states in India have integrated adaptation strategies in their public health planning through use of climate services for health.

\section{Heat action plan}

In 2010, Ahmedabad city experienced a heat wave with maximum temperature reaching $46.8^{\circ} \mathrm{C}$ and a $43.1 \%$ increase over the baseline all-cause mortality rate. Thereafter, the Ahmedabad Municipal Corporation collaborated with Indian Institute of Public Health and Natural Resources Defense Council to develop and implement a heat action plan (HAP). Ahmedabad's HAP was piloted in 2013 and fully implemented in 2014, which led to a decline in summer all-cause mortality rates ${ }^{49}$. It was associated with a reduced death rate on hot days, with more than 1100 deaths avoided each year ${ }^{50}$. Subsequently, the NCDC disseminated 'Guidelines for preparation of Action Plan-Prevention and Management of Heat-Wave' prepared by National Disaster Management Authority and 'Guidelines on Prevention and Management of Heat Related Illnesses' prepared by MoHFW to all states ${ }^{51}$. Gujarat, Telangana and Odisha have developed action plans.

\section{Decision support systems}

RIMES has developed 'Decision Support Systems' pertaining to disaster management, agriculture and public health, in collaboration with several central and state authorities in India $^{52}$, for example, SATARK in Odisha and TNSMART and CRISH in Tamil Nadu. Most of these decision support systems do not exclusively deal with public health; however, they yield health co-benefits and thus supplement adaptation efforts.

\section{Efforts by IMD}

IMD in collaboration with IITM provides a range of climate services, including heat wave guidance, air quality and aerosol monitoring forecasts, weather services for the power sector, and specialized forecasts for tourism, marine and mountain weather ${ }^{53}$.

Recently IMD has initiated 'Climate Information for Health' ${ }^{54}$ on 'experimental basis' which predicts maximum and minimum temperatures for forthcoming two weeks and provides estimation of 'favourable transmission 
windows' for development of vector-borne diseases (Malaria and Dengue) for the duration.

\section{Missing synergies: climate change and health policies in India}

The details of various active policies and missions pertaining to climate change and health in India and their implementation framework in the foregoing, clearly show that the significance of applied climate information in public health surveillance has not been fully recognized within both domains. The direct and indirect impacts of increased exposure to climate risks are unstated and unaddressed, and there is no component of climate risk management in health, in either set of policies.

Few states have taken steps to build resilience to climate risks and the efforts have been successful too. However, these models have not been scaled-up to regional or national level. Health co-benefits undeniably arise from implementation of various policies, programmes and missions, but there is no 'active demand' for climate services in the country. The climate services by IMD could serve as useful data inputs for managing health risks. There is a lot of emphasis on convergence in principle, however, inter-sectoral collaboration and/or synergies are hardly discernible in practice.

The WMO and WHO jointly define 'Climate services for health' as 'the entire iterative process of joint collaboration between relevant multidisciplinary partners to identify, generate and build capacity to access, develop, deliver, and use relevant and reliable climate knowledge to enhance health decisions, ${ }^{55}$. In the light of the above definition, there is a need to outline actions/steps required to co-develop climate services for health in India.

\section{Recommendations: an Indian perspective}

The 'Health Exemplar' to GFCS states that for successful implementation of framework, there is a need of full commitment from the health community at global, national and local levels. Six necessary and sufficient conditions are required to be met by both health and climate stakeholders for successful development and delivery of climate services for health ${ }^{56}$ :

(i) Genuine ownership and participation with all pillars of GFCS

(ii) Accountability of joint commitments

(iii) Most direct possible link to the operational, policy and technical support mechanisms of both sectors

(iv) Political and financial commitment to GFCS

(v) Interdisciplinary collaboration and coordination in all other focus areas of GFCS
In the Indian context, the following steps (Ten Commandments) are suggested for co-developing climate services for resilient public health system.

\section{Identifying common grounds}

The current delivery model of climate services for health is not demand driven. There still exist opportunities for further integration of climate information in health system and epidemiological data in NMS services. Enhanced awareness of climate risks to health and the benefits of climate services, through active involvement could result in generating an 'active demand' for climate services.

\section{Cost-benefit analysis}

A cost-benefit analysis of integrating climate information in health planning vis-à-vis public spending as well as out-of-pocket expenditure on healthcare services would facilitate identification of common grounds. Climate inaction might prove to be too costly in coming times in light of the extreme events recorded in the country during the last decade.

\section{Convening convergence}

The development policies anchored on sustainable development assume significant potential for supporting climate action. The analysis of national level climate change and health policies clearly highlights missing synergies in the two domains. The national policies objectively reflect significance of an overlapping approach of climatesustainable development inclusive growth, however, the synergy is missing in execution. Interdisciplinary collaboration and coordination in all the focus areas of GFCS, synergies in implementation strategies and convergence of efforts would be efficient as well as effective.

\section{Enabling institutions}

The process of co-developing climate services involves three primary actors - producers (NMSs, academic institutions, private corporations, regional and global climate centres), intermediary users (domain experts, technical partners and donor organizations associated with NMS) and end-users (decision makers, government planners, communities and its members $)^{56,57}$. For co-developing climate services in health, interaction, interdependence and linkages need to be built and strengthened between the various subsidiaries.

\section{Systems approach}

Climate change threatens to undermine several gains made in the health sector; and hence, adversely impact 
the overall achievements of Universal Health Coverage and SDGs. Reducing and managing health risks would require systems approach to prepare for, cope with, and recover from the health consequences of climate change. The data from demographic and health surveys for the country can be effectively used to provide information to develop and support climate-resilient health services.

\section{Evidence-based decision-making}

Vulnerability and adaptation assessment based on epidemiological, climate and socio-economic data assist in estimating climate-sensitive health risks and in prioritizing adaptation options. Non-availability of data on climate sensitive diseases is one of the biggest challenges for vulnerability assessment of the population as it limits the understanding of the impact of climatic variability on morbidity and mortality. Availability and use of data on several temporal and spatial scales would be crucial for climate risk management as well as adaptation planning. Strengthening the early warning systems in assessing integrated health risks would improve climate risk management.

\section{Interdisciplinary research}

There are enormous possibilities of research in Teleepidemiology 'wherein vegetation, meteorological and oceanographical data from satellites is used with hydrological and clinical data, to build predictive mathematical models for epidemic monitoring, ${ }^{15}$. Well-defined data sharing protocols between institutions would facilitate interdisciplinary research.

\section{Pandemic preparedness}

COVID-19 pandemic has not only colossally impacted public health but has also hugely dented economy and livelihoods at all levels. Communities, industries and governments across the world have been forced to rethink, reshape and redefine 'the normal'. Climate adaptation strategy also requires revision to encompass 'pandemic preparedness' as climate change acts as a 'threat multiplier' ${ }^{58}$ during the pandemic and aggravates risks. For example, the super cyclone 'Amphan' affected eastern parts of India and Bangladesh in May 2020. Nearly four million people were evacuated. The disaster preparedness and response plan incorporated requirement of protective gears, masks, quarantine centres and additional shelters for pandemic precautions. The risks were thus "compounded" ${ }^{59}$. While the impact of pandemic is devastating, it has also opened a policy window for climate action. The crisis provides lessons for investing in infrastructure and technologies that prevent systemic risks, including those posed by climate change.

\section{Capacity building}

Besides developing the most essential infrastructural capacity, there is also a strong need of capacity development in other three categories - human resources, procedural and institutional capacity. The first step would be awareness building among stakeholders on the information usability gap in decision making. The next steps should focus on procedural and institutional capacity building for effective implementation of the above recommendations. Capacity building needs to be an essential element of annual budget planning.

\section{Understanding the complexity of adaptation}

Climate change as well as health care are not linear systems. These are complex domains involving various modes of governance, different types of stakeholders and a wide political scale. Furthermore, India is a unique setup because of its diversity in languages, cultural backgrounds, administrative environments and also in political realities. Each factor mediates in varying degrees to the design of adaptation strategy and also influences the adaptive outcomes; be it climate change or health care. An understanding of these complex interactions should guide the review and re-imagining of effective policies and programmes.

\section{Conclusion}

The development objectives of India are firmly anchored on poverty alleviation and sustainable development. The political leadership of India champions the cause of climate justice. Development of climate services for health in India would require proactive partnerships, enabling institutions, creating sustainable infrastructure, strengthening capacities and investment in interdisciplinary research on climate-health linkages. Given the huge share of population vulnerable to climate risks, with high probability of increased risk exposure in the future, it would be a missed opportunity if health and climate actors of the country do not work together to combat the threat by shaping up an effective system of climate services for the public health system.

Disclaimer: The views expressed in the article are those of the authors and not of the organization they are affiliated.

1. IPCC, Summary for policymakers. In Climate Change 2013: The Physical Science Basis. Contribution of Working Group I to the Fifth Assessment Report of the Intergovernmental Panel on Climate Change (eds Stocker, T. F. et al.), Cambridge University Press, Cambridge, United Kingdom and New York, NY, USA, 2013. 
2. Smith, K. R. et. al., Human health: impacts, adaptation, and co-benefits. In Climate Change 2014: Impacts, Adaptation, and Vulnerability. Part A: Global and Sectoral Aspects. Contribution of Working Group II to the Fifth Assessment Report of the Intergovernmental Panel on Climate Change (eds Field, C. B. et al.), Cambridge University Press, Cambridge, United Kingdom and New York, NY, USA, 2014, pp. 709-754.

3. Shende, V. and Patil, K., Impact of environmental change on human health: an overview. Int. J. Res. Biosci., Agric. Technol., $2017, \mathbf{5}, 51-55$.

4. Bezirtzoglou, C., Dekas, K. and Charvalos, E., Climate changes, environment and infection: facts, scenarios and growing awareness from the public health community within Europe. Anaerobe, 2011, 17(6), 337-340.

5. Viennet, E. and Harley, D., Climate services for health: cooperation for climate informed dengue surveillance. Lancet, 2017, 1(4), 126-127.

6. Roy, J. et al., Exacerbating health risks in India due to climate change: Rethinking approach to health service provision. In Natural Resources Management: Concepts, Methodologies, Tools, and Applications, IGI Global, Hershey, 2017, pp. 1325-1350.

7. Heitzman, J. and Worden, R. L., India: A Country Study, Library of Congress, Area Handbook Series, United States Government Printing Office, 1996, 5th edn.

8. India's Second Biennial Update Report to the United Nations Framework Convention on Climate Change, 2018; https://unfccc. int/sites/default/files/resource/INDIA\%20SECOND\%20BUR\%20High\%20Res.pdf (accessed on 6 June 2020).

9. Census of India 2011; https://www.census2011.co.in/ (accessed on 10 June 2020).

10. Thomas, K. et al., Explaining differential vulnerability to climate change: A social science review. WIREs Climate Change, 2019, 10(2), e565.

11. Report of the Expert Group to review the methodology for measurement of poverty, Planning Commission, Govt. of India, 2014; http://www.indiaenvironmentportal.org.in/files/file/Rangarajan\%20 poverty\%20report.pdf (accessed on 2 July 2020).

12. Hoegh-Guldberg, O. et al., Impacts of $1.5^{\circ} \mathrm{C}$ global warming on natural and human systems. In Global Warming of $1.5^{\circ} \mathrm{C}$. An IPCC Special Report on the Impacts of Global Warming of $1.5^{\circ} \mathrm{C}$ above Pre-industrial Levels and Related Global Greenhouse Gas Emission Pathways, in the Context of Strengthening the Global Response to the Threat of Climate Change, Sustainable Development, and Efforts to Eradicate Poverty (eds Masson-Delmotte, V. et al.), IPCC, 2018.

13. Lemos, M., Kirchhoff, C. and Ramprasad, V., Narrowing the climate information usability gap. Nature Climate Change, 2012, 2, 789-794.

14. Gerger Swartling, A. et al., Joint knowledge production for improved climate services: Insights from the Swedish forestry sector. Environ. Policy Govern., 2019, 29(2), 97-106.

15. Mehajan, R. K., Tewary, A. and Gupta, S., Towards effective climate services: Indian context. Curr. Sci., 2019, 117(8), 1274 1280.

16. Climate services for health, World Meteorological Organization; https://public.wmo.int/en/media/news/climate-services-health (accessed on 15 July 2020).

17. About GFCS, http://www.wmo.int/gfcs/about-gfcs (accessed on 20 July 2020)

18. National Health Profile 2019, 14th issue, Central Bureau of Heath Intelligence, MoHFW, GoI, 2019; http://www.cbhidghs.nic.in/ WriteReadData/1892s/8603321691572511495.pdf (accessed on 1 August 2020).

19. World Health Organization; https://www.who.int/healthinfo/ global_burden_disease/metrics_daly/en/ (accessed on 5 August 2020).
20. State-level disease burden initiative in India; http://www. healthdata.org/disease-burden-india (accessed on 10 August 2020).

21. Tripathi, B., Diarrhoea took more lives than any other water-borne disease in India. IndiaSpend, 1 May 2018; https://www. indiaspend.com/diarrhoea-took-more-lives-than-any-other-waterborne-disease-in-india-58143/ (accessed on 11 August 2020).

22. About Pradhan Mantri Jan Arogya Yojana (PM-JAY); https://pmjay.gov.in/about/pmjay (accessed on 11 August 2020).

23. Bodansky, D. and Rajamani, L., The Evolution and Governance Architecture of the United Nations Climate Change Regime. In International Relations and Global Climate Change: New Perspectives (eds Sprinz, D. and Luterbacher, U.), MIT Press, 2017, 2nd edn.

24. WHO Guidance to Protect Health from Climate Change through Health Adaptation Planning; https://www4.unfccc.int/sites/NAPC/ Documents/Supplements/WHO\%20H-NAP\%202014.pdf （accessed on 14 August 2020).

25. WHO Health and Climate Change Survey Report: Tracking Global Progress, Geneva, 2018; https://www.who.int/globalchange/ publications/country-profiles-global-report-2019/en/ (accessed on 21 August 2020).

26. Sustainable Development Goals Knowledge Platform; https:// sustainabledevelopment.un.org/sdgs (accessed on 21 August 2020).

27. Paris Agreement, United Nations; https:/unfccc.int/sites/default/ files/english_paris_agreement.pdf (accessed on 25 August 2020).

28. About Copernicus; https://www.copernicus.eu/en/about-copernicus (accessed on 25 August 2020).

29. Climate change; https://www.copernicus.eu/en/services/climatechange (accessed on 28 August 2020).

30. Allis, E. et al., Copernicus Joining Forces with WMO on GFCS, WMO Bull., 2019, 68(2), 5-13.

31. DARE Activities India; https://www.idare-portal.org/es/data/dareactivities-india (accessed on 28 August 2020).

32. Regional Climate Outlook Forums; https://library.wmo.int/doc num.php?explnum_id=3191 (accessed on 28 August 2020).

33. About RIMES; http://www.rimes.int/?q=about-rimes (accessed on 28 August 2020).

34. Male declaration on building health systems resilience to climate change, World Health Organization, Regional Office for SouthEast Asia; https://apps.who.int/iris/handle/10665/259578 (accessed 30 August 2020).

35. National Action plan on Climate Change, Prime Minister's Council on Climate Change, Govt. of India; http://moef.gov.in/wpcontent/uploads/2018/04/Pg01-52_2.pdf (accessed on 1 September 2020).

36. India: NAPCC Process Country Case Study, GIZ, 2019; https:// www.adaptationcommunity.net/wp-content/uploads/2019/04/ giz2019-en-factsheet-nap-india-low-res.pdf (accessed on 1 September 2020).

37. Draft National Action Plan for Climate Change and Human Health, MoHFW, GoI, 2018; https://ncdc.gov.in/WriteReadData/ 1892s/27505481411548674558.pdf (accessed on 5 September 2020).

38. Minutes of the 6th Meeting of MSG of NHM held on 2 February 2019; https://nhm.gov.in/New_Updates_2018/Monitoring/MSG/ 6th-MSG-of-NHM-Minutes.pdf (accessed on 5 September 2020).

39. Kumar, V., Coping with Climate Change (Vol. II): An Analysis of India's State Action Plans on Climate Change, Centre for Science and Environment, New Delhi, 2018; http://cdn.cseindia.org/ attachments/0.40897700_1519110602_coping-climate-change-volII. pdf (accessed on 10 September 2020).

40. Implementation guidelines for National Adaptation Fund for Climate Change, Ministry of Environment Forest and Climate Change, GoI, 2015; https://www.nabard.org/auth/writereaddata/ 
File/FinalImplementationNAdaptFund.pdf (accessed on 10 September 2020).

41. Annual Report 2018-19, Ministry of Environment Forest and Climate Change, GoI; http://moef.gov.in/wp-content/uploads/ 2019/08/Annual-Report-2018-19-English.pdf (accessed on 10 September 2020).

42. Projects sanctioned under National Adaptation Fund for Climate Change, NABARD; https://www.nabard.org/content.aspx?id=585 (accessed on 10 September 2020).

43. India's intended nationally determined contribution: working towards climate justice, 2015; https://www4.unfccc.int/sites/ submissions/INDC/Published\%20Documents/India/1/INDIA\%20INDC\%20TO\%20UNFCCC.pdf (accessed on 10 September 2020).

44. Garg, A., Mishra, V. and Dholakia, H. H., Climate Change and India: Adaptation Gap (2015), Working Paper, Indian Institute of Management, Ahmedabad, 2015; https://web.iima.ac.in/assets/ snippets/workingpaperpdf/10071603592015-11-01.pdf (accessed on 11 September 2020).

45. National Health Policy 2017, MoHFW, GoI, 2017; https://main mohfw.gov.in/sites/default/files/9147562941489753121.pdf (accessed on 11 September 2020).

46. National Rural Health Mission: Framework for Implementation 2005-12, MoHFW, GoI; https://nhm.gov.in/WriteReadData/1892s/ nrhm-framework-latest.pdf (accessed on 11 September 2020).

47. National Urban Health Mission: Framework for Implementation 2013, MoHFW, GoI; https://nhm.gov.in/images/pdf/NUHM/ Implementation_Framework_NUHM.pdf (accessed on 11 September 2020).

48. Framework on Convergence, National Urban Health Mission, MoHFW, GoI; https://nhm.gov.in/images/pdf/NUHM/Frameworkon-Convergence.pdf (accessed on 11 September 2020).

49. Hess, J. et al., Building resilience to climate change: pilot evaluation of the impact of India's first heat action plan on all-cause mortality. J. Environ. Public Health, 2018, 1-8.
50. Golechha, M. and Panigrahy, R. K., COVID-19 and heatwaves: a double whammy for Indian cities. The Lancet. Planetary Health, 2020, 4(8), e315-316.

51. NCDC Quarterly Newsletter, 2019, 8(3); https://ncdc.gov.in/ WriteReadData/1892s/77052763611582199577.pdf (accessed on 11 September 2020).

52. RIMES decision support system; http://www.rimes.int/?q=dss (accessed on 15 September 2020).

53. India Meteorological Department; https://mausam.imd.gov.in/ imd_latest/contents/climate_services_daily_rainfall_maps.php (accessed on 15 September 2020).

54. Climate information for Health (Experimental basis), India Meteorological Department; http://imdpune.gov.in/hydrology/health.pdf (accessed on 23 December 2020).

55. Shumake-Guillemot, J. and Fernandez-Montoya, L. (eds), Climate Services for Health: Improving Public Health Decision-Making in a New Climate, Geneva, 2016.

56. Health Exemplar to the User Interface Platform of the Global Framework for Climate Services, World Meteorological Organization, 2014; https://gfcs.wmo.int/sites/default/files/Priority-Areas/ Health/GFCS-HEALTH-EXEMPLAR-FINAL-14152_en.pdf (accessed on 15 September 2020).

57. What do we mean by climate services? WMO Bull., 2013, 62.

58. Carter, S. et al., Co-Production in African Weather and Climate Services. Manual, Cape Town, 2019, 2nd edn.

59. Phillips, C. A. et al., Compound climate risks in the COVID-19 pandemic. Nature Climate Change, 2020, 10, 586-588.

Received 30 December 2020; revised accepted 16 March 2021

doi: $10.18520 / \mathrm{cs} / \mathrm{v} 120 / \mathrm{i} 10 / 1578-1586$ 